\title{
ANÁLISE DE DANOS MECÂNICOS E QUALIDADE DE SEMENTES DE ALGODOEIRO ${ }^{1}$
}

\author{
DANIELA COSTA SOUZA², MARIA CRISTINA DE FIGUEIREDO E ALBUQUERQUE ${ }^{3}$, \\ MARIA DE FÁTIMA ZORATO4 ${ }^{4}$, DIELLE DO CARMO CARVALHO ${ }^{5}$
}

\begin{abstract}
RESUMO - No presente trabalho objetivou-se analisar os danos mecânicos e seus efeitos na germinação e vigor de sementes de algodoeiro. Foram utilizadas amostras de cinco lotes de sementes de algodoeiro, variedade ITA-90, safra 2004/05, logo depois do processamento. As sementes foram analisadas quanto à porcentagem de danos mecânicos, teor de água, germinação e vigor (envelhecimento acelerado, germinação a baixa temperatura, comprimento de plântula e de raiz, emergência de plântulas em campo, primeira contagem e índice de velocidade de emergência). As sementes de cada amostra foram separadas nas seguintes classes: sementes inteiras, amassadas, fissuradas e cortadas, e verificadas as porcentagens de plântulas normais e anormais e de sementes deterioradas nos testes de germinação, emergência de plântulas em campo, primeira contagem e índice de velocidade de emergência para cada classe. O delineamento experimental foi o inteiramente casualizado, com cinco tratamentos (lotes) e quatro repetições. Verificou-se que a influência de danos mecânicos na qualidade das sementes depende do tamanho, da profundidade e da localização do dano. Os danos mecânicos que causam mais prejuízos nas sementes localizam-se, principalmente, nas regiões da radícula e da plúmula. Os danos mecânicos caracterizados por cortes e fissuras profundos quando atingem o embrião propiciam reduções na germinação e vigor das sementes.
\end{abstract}

Termos para indexação: Gossypium hirsutum, vigor, germinação.

\section{ANALYSIS OF THE MECHANICAL DAMAGES AND QUALITY SEEDS COTTON PLANT}

\begin{abstract}
The objective of the present study was to analyse mechanical damage and its effect on the germination and vigour of cotton seeds. Samples from five lots of cotton seeds were used, of the ITA-90 variety, 2004/05 crop, soon after processing. The seeds were analyzed for percentage of mechanical damage, moisture content, germination and vigour (accelerated ageing, cool germination, seedling and root length, seedling emergence, first count and speed emergence index tests). The seeds of each sample were separated into classes - whole, creased, cracked and cut seeds, and the percentage of normal and abnormal seedlings was verified, as well as that of deteriorated seeds in the germination tests, emergence of seedlings in the field, the first count and the emergence speed index. A randomized complete design was used, with five treatments (lots) and four replications. It was found that the influence of mechanical damage the quality of seeds depended on the size, depth and location of the damage. Mechanical damage caused more damage to the seeds mainly in the regions
\end{abstract}

${ }^{1}$ Submetido em 11/06/2007. Aceito para publicação em 13/02/2008. Parte da dissertação de mestrado do primeiro autor.

${ }^{2}$ Mestre em Agricultura Tropical, Programa de Pós-graduação em Agricultura Tropical, FAMEV/UFMT. Av. Fernando Correa da Costa $\mathrm{s} / \mathrm{n}^{\circ}$, Coxipó, Cuiabá-MT. CEP 78060-900.

${ }^{3} \mathrm{Dr}^{\mathrm{a}}$, Professora Associada, FAMEV/UFMT, Av. Fernando Correa da Costa s/nº, Coxipó, Cuiabá-MT. CEP 78060-900.mcfa@ufmt.br

${ }^{4}$ Bióloga, Sementes Aurora, Bahia. fatimazoratoaurora@terra.com.br

${ }^{5}$ Mestranda em Agricultura Tropical, FAMEV/UFMT. Cuiabá-MT. CEP 78060-900. 
of the radicle and plumule. The mechanical damage was characterized by deep cuts and fissures and when they reached the embryo there were reductions in germination and vigor.

Index terms: Gossypium hirsutum, vigor, germination.

\section{INTRODUÇÃO}

O sucesso da cultura do algodoeiro no cerrado tem sido impulsionado pelas condições de clima favorável, pelas terras planas, que permitem a mecanização total da lavoura, pelos programas de incentivo, à cultura, implementados nos estados da região e, sobretudo, pelo uso intensivo de tecnologias modernas (Embrapa, 2003).

A área plantada para algodão, no Brasil, nas safras $2005 / 2006$ e 2006/2007 foi, respectivamente, de 850.600 ha e 1.088.700 ha, com demanda potencial de sementes de $16.331 \mathrm{t}$ (Abrasem, 2007). A semente é o insumo de maior impacto sobre a produção, e de menor custo no sistema de produção do algodoeiro, correspondendo, em média a 2,3 $3,0 \%$ do custo total da lavoura, o que torna imprescindível a priorização da qualidade (Freire et al., 1999).

Do potencial de produtividade do algodão, apenas $15,9 \%$ tem sido atingido, e o aproveitamento desse potencial poderia ser elevado a $60 \%$. No Brasil, dentre as principais variáveis que têm contribuído para essas perdas, destaca-se o uso de sementes de baixa qualidade fisiológica, refletindo em estande desuniforme após a semeadura (Ribeiro et al., 2002). A danificação mecânica, juntamente com a mistura varietal, é apontada como um dos mais sérios problemas da produção de sementes. A danificação mecânica é consequência, na sua maior parte, da mecanização das atividades agrícolas, sendo um problema praticamente inevitável e o conhecimento de como ela ocorre e dos fatores que intervêm na sua intensidade podem facilitar seu controle (Carvalho e Nakagawa, 2000).

Entre as causas da perda de qualidade em sementes, destacam-se os danos mecânicos provocados principalmente durante as operações de colheita e beneficiamento (Flor et al., 2004). Como consequência da danificação mecânica as sementes apresentam-se quebradas, trincadas, fragmentadas, arranhadas e internamente danificadas. Além do prejuízo em relação ao aspecto físico, sementes com danos mecânicos são de difícil limpeza no beneficiamento com conseqüentes perdas nessa etapa, apresentam menor vigor e germinação, são mais suscetíveis ao tratamento químico e ao ataque dos microrganismos no solo (Copeland e McDonald Jr, 1995).

Durante o processamento do algodão, os processos de descaroçamento, de deslintamento e de classificação podem provocar perdas quanti-qualitativas de sementes. O algodão em caroço passa por uma série de equipamentos para a obtenção das sementes e todos eles, de alguma forma, podem provocar danificações nas sementes e prejudicar o seu potencial fisiológico.

Santiago e Usberti(1983) verificaram que o deslintamento mecânico não comprometeu significativamente os valores de germinação inicial de sementes de algodoeiro, mas causaram efeitos prejudiciais no vigor e germinação após dez meses de armazenamento. Além disso, de acordo com esses autores, quanto mais severo o deslintamento, maior a redução de qualidade.

Danificações mecânicas causam reduções no potencial fisiológico das sementes com reduções de plântulas normais aumento de plântulas anormais e infeccionadas (Popinigis, 1985). Mesmo não avaliando a incidência de danos mecânicos em sementes de algodoeiro, Bragantini et al. (1974) observaram que a presença de sementes com abrasões, cortes e amassamentos, aliado ao elevado teor de óleo de sementes de algodão, pode contribuir para perda de qualidade durante o armazenamento das mesmas.

$\mathrm{O}$ descaroçamento mecânico não teve efeito prejudicial imediato sobre o vigor das sementes de algodoeiro, porém ocasionaram decréscimo do vigor das sementes, quando avaliado por meio dos testes de primeira contagem, envelhecimento acelerado, emergência e índice de velocidade de emergência de plântulas em campo, durante o armazenamento (Silva et al., 2006). Esses autores comentaram que este decréscimo na qualidade das sementes pode ser tanto conseqüência do descaroçamento como do deslintamento.

Desta forma, os objetivos neste trabalho foram analisar os danos mecânicos e seus efeitos na germinação e vigor das sementes de algodoeiro.

\section{MATERIAL E MÉTODOS}

O experimento foi realizado no Laboratório de Sementes da Associação dos Produtores de Sementes de Mato Grosso (APROSMAT), em Rondonópolis, Mato Grosso, no período 
de agosto de 2005 a junho de 2006, com sementes de algodoeiro, cultivar ITA-90, da safra 2004/05, produzidas na região sul de Mato Grosso.

Foram utilizadas amostras de cinco lotes de sementes deslintadas e classificadas pelo tamanho e pela densidade, previamente identificadas e homogeneizadas. Foi determinada a massa de 1000 sementes (Brasil, 1992) de cada lote e depois as mesmas foram avaliadas por meio dos seguintes testes: teor de água, germinação, vigor (envelhecimento acelerado, germinação a baixa temperatura, comprimento de plântula e de raiz, emergência de plântulas em campo, primeira contagem e índice de velocidade de emergência).

Os testes de teor de água (TA) e de germinação foram realizados seguindo critérios das Regras para Análise de Sementes (Brasil, 1992). No teste de germinação (TG) foram usadas quatro repetições de 50 sementes, a semeadura em substrato de papel na forma de rolos, umedecidos em água, na quantidade de duas e meia vezes a massa do papel seco, a temperatura de $25^{\circ} \mathrm{C}$ e fotoperíodo de oito horas. As avaliações foram feitas aos quatro e sete dias após a semeadura, sendo os resultados expressos em porcentagem de plântulas normais, plântulas anormais e sementes deterioradas. Juntamente com o teste de germinação foi realizado o teste de primeira contagem (PC), conforme Nakagawa (1999).

$\mathrm{O}$ teste de envelhecimento acelerado (EA) foi realizado no método de "gerbox" de acordo com as recomendações de Marcos Filho (1999). Os comprimentos de raiz (CR) e de plântula $(\mathrm{CP})$ foram conduzidos segundo metodologia descrita por Nakagawa (1999) e o teste de germinação a baixa temperatura segundo Dias e Alvarenga (1999). O teste de emergência de plântulas (EC) em campo foi conduzido em canteiros na APROSMAT, em solo arenoso com 4 a $5 \%$ de argila. Foram utilizadas quatro subamostras de 50 sementes por repetição na profundidade de semeadura de $3 \mathrm{~cm}$ em todas as repetições. A porcentagem de emergência em campo foi determinada aos 12 dias após a semeadura. Concomitante a esse teste foi realizado o índice de velocidade de emergência de plântulas (IVE), contando-se diariamente as plântulas normais emergidas durante 12 dias, até a estabilização do estande. Foram consideradas emergidas as plântulas que apresentavam os cotilédones acima do solo e o índice de velocidade foi calculado de acordo com Maguire (1962).

Depois, foi realizado o detalhamento dos danos mecânicos de cada lote, em quatro repetições de 250 gramas, sendo calculado o percentual de sementes de cada classe: sementes sem danos (inteiras), amassadas, fissuradas e cortadas. As sementes da classe amassada caracterizavam- se pela presença de tegumentos amassados. As sementes cortadas tinham cortes no tegumento, atingindo a estrutura interna da semente. As sementes fissuradas ou trincadas foram aquelas com danos mecânicos expressivos no tegumento, atingindo ou não as estruturas internas; as fissuras foram mais superficiais do que os cortes.

A avaliação de danos mecânicos foi realizada visualmente e com o uso de lupa de seis vezes de aumento. Após a separação, as sementes de cada classe foram analisadas separadamente pelos testes de germinação e emergência de plântulas em campo, conforme descrição acima, e verificadas as porcentagens de plântulas normais e anormais e de sementes deterioradas. Para as sementes inteiras, foram utilizadas quatro repetições de 50 sementes. Para as classes de sementes amassadas, fissuradas e cortadas, o número de sementes utilizado nos testes foi de acordo com a quantidade de sementes danificadas de cada classe, que variou de 1,88 a 12,8 gramas/classe.

$\mathrm{O}$ delineamento experimental foi $\mathrm{o}$ inteiramente casualizado, com cinco tratamentos (lotes) e quatro repetições. A análise de variância foi realizada em separado para cada variável. Quando necessário, os dados foram transformados para atenderem os pressupostos de normalidade e homogeneidade.

Os resultados dos testes de germinação e de vigor (emergência de plântulas em campo, germinação a baixa temperatura e envelhecimento acelerado) foram correlacionados com os resultados de sementes inteiras e de danos mecânicos (amassadas, fissuradas e cortadas) pelo teste de correlação de Pearson.

\section{RESULTADOS E DISCUSSÃO}

Pela análise da qualidade dos lotes (Tabela 1), foi possível verificar variações nos diferentes parâmetros avaliados. Melhor potencial fisiológico foi observado nos lotes 2 e 3, seguidos pelos lotes 1 e 5 , considerando-se os resultados observados nos testes de germinação, envelhecimento acelerado e emergência de plântulas em campo. A germinação das sementes dos cinco lotes foi superior ao padrão nacional que é de $70 \%$ para sementes genéticas e de $75 \%$ para as demais classes (MAPA, 2005).

Os percentuais de danos mecânicos por classe nos cinco lotes encontram-se na Tabela 2. Nota-se que maiores porcentagens de sementes inteiras, aparentemente sem danos, foram observadas nos lotes 3 e 5 . Nesses lotes foram verificadas as menores porcentagens de sementes fissuradas e cortadas e seus tegumentos eram perfeitamente 
desenvolvidos, sem lesões ou danos mecânicos visíveis. No lote 4 também foram observadas porcentagens baixas de sementes fissuradas e cortadas. Na classe amassada, as menores porcentagens foram verificadas nas sementes dos lotes 1,2 e 5 . No total, os lotes não superaram $12,1 \%$ de danos mecânicos, o que indica estar dentro de um limite tolerável, pois somente acima de $20 \%$ são considerados excessivos (Bragachini et al., 1992).

TABELA 1. Qualidade inicial dos lotes de sementes de algodoeiro, cultivar ITA-90 avaliada por meio dos testes de germinação, vigor e teor de água.

\begin{tabular}{|c|c|c|c|c|c|}
\hline \multirow{2}{*}{ Variável } & \multicolumn{5}{|c|}{ Lotes } \\
\hline & 1 & 2 & 3 & 4 & 5 \\
\hline TA (\%) & $9,8 \mathrm{~B}$ & $9,9 \mathrm{~B}$ & $10,6 \mathrm{AB}$ & $10,5 \mathrm{AB}$ & $11,0 \mathrm{~A}$ \\
\hline TG (\%) & $81 \mathrm{BC}$ & $85 \mathrm{AB}$ & $90 \mathrm{~A}$ & $77 \mathrm{C}$ & $86 \mathrm{Ab}$ \\
\hline EA $(\%)$ & $92 \mathrm{~A}$ & $91 \mathrm{~A}$ & $91 \mathrm{~A}$ & $78 \mathrm{~B}$ & $80 \mathrm{~B}$ \\
\hline TA/EA (\%) & $26,6 \mathrm{~A}$ & $28,4 \mathrm{~A}$ & $28,7 \mathrm{~A}$ & $29,5 \mathrm{~A}$ & $29,7 \mathrm{~A}$ \\
\hline GBT (\%) & $84 \mathrm{~A}$ & $86 \mathrm{~A}$ & $89 \mathrm{~A}$ & $72 \mathrm{~B}$ & $86 \mathrm{~A}$ \\
\hline $\mathrm{EC}(\%)$ & $92 \mathrm{AB}$ & $94 \mathrm{~A}$ & $90 \mathrm{AB}$ & $76 \mathrm{C}$ & $88 \mathrm{~B}$ \\
\hline IVE & $14,31 \mathrm{~A}$ & $14,67 \mathrm{~A}$ & $14,46 \mathrm{~A}$ & $11,82 \mathrm{~B}$ & $13,90 \mathrm{~A}$ \\
\hline $\mathrm{CP}(\mathrm{cm})$ & $19,36 \mathrm{~A}$ & $19,77 \mathrm{~A}$ & $11,13 \mathrm{~B}$ & $14,56 \mathrm{~B}$ & $18,07 \mathrm{~A}$ \\
\hline $\mathrm{CR}(\mathrm{cm})$ & $12,83 \mathrm{~A}$ & $13,12 \mathrm{~A}$ & $6,00 \mathrm{C}$ & $8,69 \mathrm{~B}$ & $12,11 \mathrm{~A}$ \\
\hline
\end{tabular}

Médias seguidas pelas mesmas letras, na linha, não diferem entre si a 5\% de probabilidade pelo teste de Tukey.

TA - teor de água; TG - germinação; EA - germinação após envelhecimento acelerado; TA/EA - teor de água após o envelhecimento acelerado; GBT germinação à baixa temperatura; EC - emergência de plântulas em campo; IVE - índice de velocidade de germinação; CP - comprimento de plântula; CR - comprimento de raiz.

TABELA 2. Porcentagem de sementes inteiras, amassadas, fissuradas e cortadas, observada nos lotes de sementes.

\begin{tabular}{ccccc}
\hline Lotes & \% Inteiras & \% Amassadas & \% Fissuradas & \% Cortadas \\
\hline 1 & $87,9 \mathrm{c}$ & $0,25 \mathrm{c}$ & $8,16 \mathrm{a}$ & $3,69 \mathrm{a}$ \\
2 & $90,8 \mathrm{~b}$ & $0,52 \mathrm{bc}$ & $5,75 \mathrm{~b}$ & $2,71 \mathrm{~b}$ \\
3 & $94,4 \mathrm{a}$ & $1,09 \mathrm{ab}$ & $2,77 \mathrm{c}$ & $1,71 \mathrm{c}$ \\
4 & $91,2 \mathrm{~b}$ & $1,19 \mathrm{a}$ & $5,47 \mathrm{~b}$ & $2,14 \mathrm{bc}$ \\
5 & $94,0 \mathrm{a}$ & $0,71 \mathrm{abc}$ & $3,44 \mathrm{c}$ & $1,83 \mathrm{c}$ \\
\hline $\mathrm{CV}(\%)$ & 0,80 & 56,02 & 19,95 & 18,10 \\
\hline
\end{tabular}

Médias seguidas pela mesma letra minúscula na coluna, não diferem entre si pelo teste de Tukey a 5\%.

Comparando os resultados observados nos testes de germinação e vigor (Tabela 1) com os de danos mecânicos (Tabela 2), constatou-se melhor desempenho fisiológico no lote 3 , exceto nos resultados observados nos testes de comprimento de plântulas e de raízes, conseqüência de sua alta porcentagem de sementes inteiras, e baixa porcentagem de sementes fissuradas e cortadas.

Nos lotes 1, 2 e 3, foram observados maiores valores de germinação e vigor, embora com menores porcentagens de sementes inteiras e amassadas. No lote 4 obtiveram-se os menores valores de germinação e de vigor avaliado por meio dos testes (EA, GBT, EC, IVE, CP e CR) provavelmente 
devido a maior porcentagem de sementes amassadas. Trincas ou rachaduras situadas, de forma superficial, são facilmente detectadas, mas danos menores ou micro danos, mesmo que invisíveis a olho nu, dependendo da sua localização, podem ocasionar redução significativa na qualidade das sementes (Flor et al., 2004).

Os resultados de germinação observados nas sementes separadas por classes (inteiras, amassadas, fissuradas e cortadas) encontram-se na Tabela 3. Verificou-se nas sementes classificadas como inteiras, germinação na faixa de 87,5 a $97,5 \%$ sem diferenças significativas. No lote 5 foi verificada porcentagem de plântulas anormais de $12,5 \%$.

A porcentagem de germinação das sementes da classe amassada não diferiu estatisticamente entre os lotes, mas variou de 54,3 (lote 3 ) a 100,0\% (lote 2). A variação foi alta para essa classe, provavelmente devido às diferenças de profundidade e localização do dano nas sementes e obtenção de algumas repetições com valores iguais a zero no lote 3 . Quando se comparou a porcentagem de germinação das sementes da classe amassada dos lotes $1,3,4$ e 5, foram observadas menor germinação em relação às sementes inteiras. Ainda nessa classe, o lote 3 apresentou maior porcentagem de sementes mortas. Danos mecânicos imediatos e latentes fazem com que as sementes mobilizem energia com o objetivo de cicatrizar o tecido e como consequência, a energia remanescente não é suficiente para que o processo de germinação se complete (Carvalho e Nakagawa, 2000).

$\mathrm{Na}$ classe fissurada, houve um grande decréscimo na germinação das sementes em relação às sementes inteiras, e no lote 3 , foi observada $26,0 \%$ de perda de germinação (Tabela 3). Nessa classe, no lote 1 a germinação foi mais elevada $(59,3 \%)$. Entretanto, sementes de todos os lotes apresentaram alta porcentagem de plântulas anormais $(21,5 \%$ a 46,5\%). Nos lotes 3 e 4 foram observadas porcentagens de sementes mortas acima de $40 \%$. Nas sementes da classe cortada foram observados os menores valores de germinação em relação às demais classes. Nos lotes 3,4 e 5 os índices de sementes mortas foram muito elevados, $64,3 \% ; 60,8 \% \mathrm{e}$ $42,8 \%$, respectivamente. Os danos ocasionados por fissuras e cortes foram os que mais prejudicaram a germinação das sementes, quando as mesmas foram analisadas individualmente.

TABELA 3. Plântulas normais e anormais e sementes mortas (\%), no teste de germinação, provenientes de sementes dos 5 lotes estudados.

\begin{tabular}{|c|c|c|c|c|c|c|}
\hline \multirow{2}{*}{ Classes } & \multicolumn{5}{|c|}{ Lotes } & \multirow{2}{*}{$\mathrm{CV}(\%)$} \\
\hline & 1 & 2 & 3 & 4 & 5 & \\
\hline \multicolumn{7}{|l|}{ INTEIRAS } \\
\hline Normais & $97,5 \mathrm{~A}$ & $97,5 \mathrm{~A}$ & $90,0 \mathrm{~A}$ & $87,5 \mathrm{~A}$ & $87,5 \mathrm{~A}$ & 10,12 \\
\hline Anormais & 2,5 & 0 & 7,5 & 7,5 & 12,5 & \\
\hline Mortas & 0 & 2,5 & 2,5 & 5,0 & 0 & \\
\hline \multicolumn{7}{|l|}{ AMASSADAS } \\
\hline Normais & $82,5 \mathrm{~A}$ & $100,0 \mathrm{~A}$ & $54,3 \mathrm{~A}$ & $83,0 \mathrm{~A}$ & $75,0 \mathrm{~A}$ & 28,16 \\
\hline Anormais & 7,5 & 0 & 13,6 & 7,1 & 21,4 & \\
\hline Mortas & 10,0 & 0 & 32,3 & 9,8 & 3,5 & \\
\hline \multicolumn{7}{|l|}{ FISSURADAS } \\
\hline Normais & $59,3 \mathrm{~A}$ & $55,3 \mathrm{AB}$ & $26,0 \mathrm{~B}$ & $35,8 \mathrm{AB}$ & $35,8 \mathrm{AB}$ & 21,29 \\
\hline Anormais & 37,3 & 37,5 & 26,3 & 21,5 & 46,5 & \\
\hline Mortas & 3,5 & 7,0 & 47,5 & 43,0 & 18,0 & \\
\hline \multicolumn{7}{|l|}{ CORTADAS } \\
\hline Normais & $43,0 \mathrm{AB}$ & $55,0 \mathrm{~A}$ & $7,0 \mathrm{C}$ & $10,8 \mathrm{BC}$ & $14,3 \mathrm{BC}$ & 47,11 \\
\hline Anormais & 53,5 & 36,8 & 28,8 & 28,5 & 43,0 & \\
\hline Mortas & 3,5 & 8,5 & 64,3 & 60,8 & 42,8 & \\
\hline
\end{tabular}

Letras maiúsculas iguais na linha não diferem entre si a 5\% pelo teste de Tukey.

* análise estatística realizada com dados transformados para arcse (raiz(x/100)). 
As classes de sementes amassadas, fissuradas e cortadas no lote 3 tinham danos profundos, razão da menor germinação nessas sementes. Já nos lotes 1 e 2, os danos eram mais superficiais, por isso, a obtenção de valores mais elevados no teste de germinação.

Castro et al. (2004) observaram que as fissuras no tegumento causam danos ao embrião e resultam em lixiviação de solutos e conseqüentemente, em perda de viabilidade. Da mesma forma, pode-se afirmar que os cortes também podem proporcionar perdas na qualidade das sementes e essas perdas serão maiores dependendo da localização e profundidade dos danos mecânicos na semente.

Os resultados no teste de emergência de plântulas em campo, provenientes de sementes separadas por classes (inteiras, amassadas, fissuradas e cortadas), encontramse na Tabela 4. Verifica-se que as sementes classificadas como inteiras apresentaram emergência na faixa de $87,5 \%$ a $92,5 \%$ e os lotes não diferiram entre si. No lote 5 observouse porcentagem de plântulas mortas de $12,5 \%$.

TABELA 4. Porcentagens de plântulas normais, de plântulas anormais e de sementes mortas, no teste de emergência em campo, oriundas de sementes classificadas como inteiras e danificadas.

\begin{tabular}{|c|c|c|c|c|c|}
\hline \multirow{2}{*}{ Classes } & \multicolumn{5}{|c|}{ Lotes } \\
\hline & 1 & 2 & 3 & 4 & 5 \\
\hline \multicolumn{6}{|l|}{ INTEIRAS } \\
\hline Normais & $92,5 \mathrm{~A}$ & $92,5 \mathrm{~A}$ & $90,0 \mathrm{~A}$ & $92,5 \mathrm{~A}$ & $87,5 \mathrm{~A}$ \\
\hline Anormais & 7,5 & 7,5 & 0 & 0 & 0 \\
\hline Mortas & 0 & 0 & 10 & 7,5 & 12,5 \\
\hline \multicolumn{6}{|l|}{ AMASSADAS } \\
\hline Normais & $65,0 \mathrm{~A}$ & $70,8 \mathrm{~A}$ & $48,0 \mathrm{~A}$ & $83,0 \mathrm{~A}$ & $89,3 \mathrm{~A}$ \\
\hline Anormais & 12,5 & 8,3 & 10,8 & 7,3 & 3,5 \\
\hline Mortas & 22,5 & 20,8 & 41,3 & 9,8 & 7,3 \\
\hline \multicolumn{6}{|l|}{ FISSURADAS } \\
\hline Normais & $49,0 \mathrm{AB}$ & $68,8 \mathrm{~A}$ & $33,9 \mathrm{AB}$ & $14,3 \mathrm{AB}$ & $10,7 \mathrm{~B}$ \\
\hline Anormais & 13,5 & 20,5 & 3,5 & 3,6 & 3,6 \\
\hline Mortas & 37,5 & 10,8 & 62,6 & 82,1 & 85,7 \\
\hline \multicolumn{6}{|l|}{ CORTADAS } \\
\hline Normais & $9,6 \mathrm{~B}$ & $37,1 \mathrm{~A}$ & $0 \mathrm{C}$ & $0 \mathrm{C}$ & $0 \mathrm{C}$ \\
\hline Anormais & 23,9 & 9,2 & 0 & 0 & 0 \\
\hline Mortas & 66,4 & 53,7 & 100 & 100 & 100 \\
\hline
\end{tabular}

Letras maiúsculas iguais na linha não diferem entre si a 5\% pelo teste de Tukey.

* análise estatística realizada com dados transformados para $\operatorname{arcsen}(\operatorname{raiz}(\mathrm{x} / 100))$.

Não houve diferença significativa na porcentagem de emergência de plântulas provenientes das sementes da classe amassada entre os lotes, mas foi observada variação de $48,0 \%$ (lote 3 ) a $89,3 \%$ (lote 5), provavelmente devido às diferenças na profundidade e localização dos danos, sendo que no lote 3 foi observada maior incidência de sementes mortas $(41,3 \%)$. 
A redução na porcentagem de emergência de plântulas em campo a partir dessas sementes com esse tipo de dano, em relação à verificada na classe de sementes inteiras foi maior do que a verificada na porcentagem de germinação.

Na classe fissurada, o decréscimo na qualidade em relação às sementes inteiras foi maior do que na classe amassada, sendo que no lote 5 obteve-se a menor porcentagem de emergência $(10,7 \%)$ e elevada quantidade de sementes mortas (85,7\%), e no lote 4 observou-se $82,1 \%$ de sementes mortas. As sementes da classe cortadas apresentaram os valores de emergência mais baixos em relação às demais classes. Não houve emergência de plântulas a partir das sementes provenientes dos lotes 3, 4 e 5, com incidência de $100 \%$ de sementes mortas.

$\mathrm{Na}$ Tabela 5 encontram-se os valores das correlações dos testes de germinação e vigor, com os valores porcentuais de sementes inteiras e com danos mecânicos. Verificou-se que no lote 1 ocorreram correlações significativas negativas entre os resultados de germinação a baixa temperatura e de germinação e a quantidade de sementes cortadas e fissuradas. Também foram observadas correlações significativas negativas entre os resultados de germinação e a quantidade de sementes amassadas, cortadas e fissuradas, no lote 2 , e a quantidade de sementes amassadas e fissuradas no lote 4.

TABELA 5. Valores das correlações entre os resultados dos testes de germinação e de vigor e os resultados de sementes inteiras e com danos mecânicos.

\begin{tabular}{lllllll}
\hline Variáveis & Variáveis & Lote 1 & Lote 2 & Lote 3 & Lote 4 & Lote 5 \\
\hline GBT & Inteiras & $0,8305^{* *}$ & $0,2309 \mathrm{~ns}$ & $-0,5644 \mathrm{~ns}$ & $0,1328 \mathrm{~ns}$ & $-0,7825^{*}$ \\
GBT & Amassadas & $0,1834 \mathrm{~ns}$ & $-0,5239 \mathrm{~ns}$ & $0,3292 \mathrm{~ns}$ & $-0,0179 \mathrm{~ns}$ & $0,4150 \mathrm{~ns}$ \\
GBT & Cortadas & $-0,7109^{*}$ & $0,0197 \mathrm{~ns}$ & $0,4897 \mathrm{~ns}$ & $-0,3393 \mathrm{~ns}$ & $0,9200^{* *}$ \\
GBT & Fissuradas & $-0,8475^{* *}$ & $-0,2601 \mathrm{~ns}$ & $0,5985 \mathrm{~ns}$ & $-0,0658 \mathrm{~ns}$ & $0,6786^{*}$ \\
GEA & Inteiras & $-0,9317^{* *}$ & $-0,1134 \mathrm{~ns}$ & $-0,3354 \mathrm{~ns}$ & $-0,7038^{*}$ & $-0,3427 \mathrm{~ns}$ \\
GEA & Amassadas & $-0,3177 \mathrm{~ns}$ & $0,1648 \mathrm{~ns}$ & $0,1519 \mathrm{~ns}$ & $0,7717^{*}$ & $-0,1480 \mathrm{~ns}$ \\
GEA & Cortadas & $0,9112^{* *}$ & $-0,1187 \mathrm{~ns}$ & $0,6452^{*}$ & $0,4557 \mathrm{~ns}$ & $0,5928 \mathrm{~ns}$ \\
GEA & Fissuradas & $0,9025^{* *}$ & $0,3509 \mathrm{~ns}$ & $0,2282 \mathrm{~ns}$ & $0,6714^{*}$ & $0,3230 \mathrm{~ns}$ \\
TG & Inteiras & $0,9720^{* *}$ & $0,9469^{* *}$ & $0,0291 \mathrm{~ns}$ & $0,5744 \mathrm{~ns}$ & $0,2049 \mathrm{~ns}$ \\
TG & Amassadas & $0,3183 \mathrm{~ns}$ & $-0,8210^{* *}$ & $-0,1381 \mathrm{~ns}$ & $-0,7239^{*}$ & $-0,6387 *$ \\
TG & Cortadas & $-0,9759^{* *}$ & $-0,8522^{* *}$ & $-0,2397 \mathrm{~ns}$ & $-0,0623 \mathrm{~ns}$ & $0,3952 \mathrm{~ns}$ \\
TG & Fissuradas & $-0,9280^{* *}$ & $-0,9035^{* *}$ & $0,1178 \mathrm{~ns}$ & $-0,6416^{*}$ & $-0,2383 \mathrm{~ns}$ \\
EC & Inteiras & $-0,7183^{*}$ & $-0,9427^{* *}$ & $-0,5653 \mathrm{~ns}$ & $-0,6640^{*}$ & $-0,8026^{* *}$ \\
EC & Amassadas & $0,0062 \mathrm{~ns}$ & $0,6899^{*}$ & $0,5383 \mathrm{~ns}$ & $0,6065^{*}$ & $0,8693^{* *}$ \\
EC & Cortadas & $0,5630 \mathrm{~ns}$ & $0,9587^{* *}$ & $0,4567 \mathrm{~ns}$ & $0,7451^{*}$ & $0,4245 \mathrm{~ns}$ \\
EC & Fissuradas & $0,7465^{* *}$ & $0,8002^{* *}$ & $0,5089 \mathrm{~ns}$ & $0,5467 \mathrm{~ns}$ & $0,7766^{*}$ \\
\hline
\end{tabular}

** significativo a $1 \%$ de probabilidade; * significativo a $5 \%$ de probabilidade; ns - não significativo pelo teste de correlação de Pearson.

TG - germinação; GEA - germinação após envelhecimento acelerado; GBT - germinação à baixa temperatura; EC - emergência de plântulas em campo.

Embora não tenham sido verificadas correlações negativas significativas entre todos os testes e todos os lotes, na análise conjunta observou-se melhor desempenho das sementes dos lotes 1 e 2 avaliados por meio dos testes de germinação e vigor. No entanto, nesses lotes foram observadas as menores porcentagens de sementes inteiras, e de maneira geral, maior incidência de sementes fissuradas e cortadas (Tabela 2). Os danos nas sementes dos lotes 1 e 2 foram mais superficiais que os danos dos demais lotes. Os teores de água nesses lotes foram menores que nos demais e, quanto menor o teor de água das sementes, maior a ocorrência de danos mecânicos por cortes e fissuras (Delouche, 1981).

Nos lotes 4 e 5 foram observados os piores desempenhos 
das sementes avaliados por meio dos testes de germinação e de vigor (Tabela 1). Nesses lotes, juntamente com o lote 3 , obteve-se as maiores porcentagens de sementes inteiras (Tabela 2). Esse baixo desempenho pode ser explicado, provavelmente, à incidência de danos mais profundos, com maior prejuízo nas sementes, mesmo tendo, esses lotes, no total, menor quantidade de danos (Tabela 2).

Nas sementes de algodoeiro, além da proteção do tegumento, há outro fator que oferece proteção ao embrião que é a pluma e o línter. No entanto, essa proteção é quebrada pela retirada da pluma e do línter por descaroçadores e deslintamento, sendo que nessas etapas ocorrem as maiores incidências de danos mecânicos. Conforme observado, a profundidade do dano na semente é um fator importante na redução de qualidade, assim como a localização do mesmo nas sementes. Os danos mais prejudiciais situam-se nas duas extremidades da semente, na extremidade inferior da radícula, ou seja, na região basal e no lado oposto, na região apical.

Alguns danos, embora pareçam ser insignificantes, podem causar inviabilidade da semente, como nos casos dos amassamentos. Em outros casos, danos profundos, como fissuras ou cortes, podem não causar inviabilidade na semente, por não ter atingido uma parte essencial da semente. Em outras situações, mesmo não causando a morte, podem aparecer sinais de anormalidade na plântula, como raiz bifurcada, encurtada ou engrossada, caule ou raiz com fenda, e cotilédones quebrados. Nesse caso, as sementes podem germinar, mas as plântulas não serão vigorosas.

\section{CONCLUSÕES}

A influência de danos mecânicos na qualidade das sementes depende do tamanho, da profundidade e da localização do dano.

Os danos mecânicos que causam mais prejuízos nas sementes localizam-se, principalmente, nas regiões da radícula e da plúmula.

Os danos mecânicos caracterizados por cortes e fissuras profundos quando atingem o embrião propiciam reduções na germinação e vigor das sementes.

\section{AGRADECIMENTOS}

À equipe de analistas da APROSMAT, e a Capes pela bolsa concedida no primeiro ano do curso.

\section{REFERÊNCIAS}

ABRASEM. Associação Brasileira de Sementes e Mudas. Estatística da produção. Anuário Abrasem, 2007. Pelotas, p. 29.2007.

BRAGACHINI, M.; BONETTO, L.; GIL, R.; GUELIELMETTI, M. Cosecha de soja: aspectos principales para el equipamiento, regulaciony puesta apuntode los equipos cosechadores. In: PROGRAMA COPERATIVO PARA EL DESARROLLO TECNOLÓGICO AGROPECUARIO DEL CONO SUR. 1., 1992, Montevideo, Producción de soja. Montevideo: IICA - PROCISUR, 1992. p. 223-234.

BRAGANTINI, C.; MARCOS FILHO J.; ABRAHÃO, J.T.M.; GODOY, R. Avaliação do comportamento de sementes de algodoeiro (Gossypium hirsutum L.) durante o armazenamento. Anais da Escola Superior de Agricultura Luiz de Queiroz, v.31, n.11, p.175-185, 1974.

BRASIL. Ministério da Agricultura e Reforma Agrária. Secretaria Nacional de Defesa Agropecuária. Departamento Nacional de Defesa Vegetal. Coordenação de Laboratório Vegetal. Regras para análise de sementes. Brasília, DF, 1992. $365 \mathrm{p}$.

CARVALHO, N.M.; NAKAGAWA, J. Sementes: ciência, tecnologia e produção. 4. ed. Jaboticabal: FUNEP, 2000. 588 p.

CASTRO, R.D. de.; BRADFORD, K.J.; HILHORST, H.W.M. Desenvolvimento de sementes e conteúdo de água. In: FERREIRA, A. G.; BORGHETTI, F. (Org.). Germinação: do básico ao aplicado. Porto Alegre: Artmed, 2004. p.50-67.

COPELAND, L.O.; McDONALD JUNIOR, M.B. Principles of seed science and technology. 3. ed. New York: Chapman and Hall, 1995. 409 p.

DELOUCHE, J.C. Harvest and post harvest factors affecting the quality of cotton planting seed and seed quality evaluation. In: BELWIDE COTTON PRODUCTION RESEARCH CONFERENCE. New Orleans, 1981. Proceedings... Memphis: National Cotton Council of America, 1981. p.289305.

DIAS, D.C.F.S.; ALVARENGA, E.M. Teste de germinação a baixa temperatura. In: KRZYZANOWSKI, F.C.; VIEIRA, R.D.; FRANÇA NETO, J.B. (Ed.). Vigor de sementes: conceitos e testes. Londrina: ABRATES, 1999. p.71-74.

EMBRAPA ALGODÃO. Sistemas de produção, cultura do algodão no cerrado. Jan/2003. Disponível em: $<$ http:// sistemasdeproducao.cnptia.embrapa.br/FontesHTML/ Algodao/AlgodaoCerrado/index.htm>. Acesso em: 23 abr. 2005. 
FREIRE, E.C.; FARIAS, F.J.C.; WATANABE, P.A.; AGUIAR, P.H. Produção de sementes. In: Mato Grosso: liderança e competitividade. Rondonópolis: Fundação MT; Campina Grande: Embrapa-CNPA, 1999. 182p. (Fundação MT. Boletim, 3).

FLOR, E.P.O.; CICERO, S.M.; FRANÇA NETO, J.de B.; KRZYZANOWSKI, F.C. Avaliação de danos mecânicos em sementes de soja por meio da análise de imagens. Revista Brasileira de Sementes, v.26, n.1, p.67-75, 2004.

MAGUIRE, J.D. Speed of germination-aid in selection and evaluation for seedling emergence and vigor. Crop Science, v.2, n.2, p.176-177, 1962.

MAPA, Ministério de Agricultura, Pecuária e Abastecimento. Instrução Normativa $\mathbf{n}^{\mathbf{0}}$ 25, 16/12/2005. Anexo 5. 2005. Disponível em: <http:/www.abrasem.com.br/legislacao_ sac/01producao_e_comercio/anexos/031_anexo_I_algodao. doc $>$. Acesso em: 23 set. 2006.

MARCOS FILHO, J. Testes de vigor: importância e utilização. In: KRZYZANOWSKI, F. C.; VIEIRA, R.D.; FRANÇA-NETO, J.B. (Ed.). Vigor de sementes: conceitos e testes. Londrina: ABRATES, 1999. cap.1, p.1-21.

NAKAGAWA, J. Testes de vigor baseados no desempenho de plântulas. In: KRZYZANOWSKI, F.C.; VIEIRA, R.D.; FRANÇA NETO, J.B. (ed.). Vigor de sementes: conceitos e testes. Londrina: Abrates, 1999. cap. 2, p.1-24.

POPINIGIS, F. Fisiologia de sementes. 2. ed. Brasília: [s.n], 1985. 289 p.

RIBEIRO, U.P.; PINHO, E.V.R.V.; GUIMARÃES, R.M.; VIANA,L.S.Determinaçãodopotencialosmóticoedoperíodo de embebição utilizados no condicionamento fisiológico de sementes de algodão. Ciência e Agrotecnologia, v.26, n.5, p.911-917, 2002.

SANTIAGO, I.M.; USBERTI, R. Deslintamento mecânico e seu efeito na qualidade de sementes de algodoeiro. Revista Brasileira de Sementes, v.5, n.2, p.29-36, 1983.

SILVA, J.C.; ALBUQUERQUE, M.C.F.; MENDONÇA, E.A.F.; KIM, M.E. Desempenho de sementes de algodão após o processamento e armazenamento. Revista Brasileira de Sementes, v.28, n.1, p.79-85, 2006. 